\title{
Crescer entre seres
}

Patrícia Postali Cruz

Doutoranda em Antropologia Social

Universidade Federal de Santa Catarina 
Estar em campo em espaços rurais é descobrir um universo de relações e detalhes onde germinar a vida e manter corpos é tarefa diária para aqueles que se dedicam ao entrelaçamento do mundo com não-humanos. A tarefa de descrever técnicas entremeadas com temperaturas, sons, plantas, chuvas, animais e tantos outros agentes parece ser ainda um desafio na descrição etnográfica. Nesse contexto, a fotografia se apresenta como uma ferramenta com grande potencial na documentação e apresentação dos dados etnográficos. Esse ensaio fotoetnográfico tem como objetivo apresentar ao leitor os processos de crescimento e desenvolvimento de plantas, animais e pessoas bem como os processos técnicos envolvidos no "crescer feijão". O plantio e desenvolvimento, que segue nas imagens desta prancha, se deu entre os meses de setembro e novembro do ano de 2016. Plantar feijão exige uma série de cuidados, observações e preparos. Onécio e Evani, interlocutores de minha pesquisa de doutorado, fazem o plantio conjuntamente. Acompanhados de máquinas com tecnologia simples e artefatos reaproveitados, o plantio do feijão ocorre de forma sincronizada, seja na sonoridade das máquinas, seja nos gestos dos corpos, seja na precisão dos espaços entre as plantas. O terreno íngreme e o solo arado com terra fofa dificultam o trabalho dos animais que ralam a terra e dos agricultores que plantam o feijão. O processo de plantar vem logo em seguida do arar. Com uma trilhadeira feita por ele, Onécio faz os trilhos, onde serão plantados os feijões, conjuntamente com o cavalo. Evani planta com uma máquina especial para plantar sementes, a qual enterra a semente no solo. Nesse sentido, viver entre processos de crescimento e colheita (morte) configura muito mais do que um fazer, mas um modo de habitar o mundo onde pessoas, não-humanos e materialidades técnicas se criam e se transformam cotidianamente. 


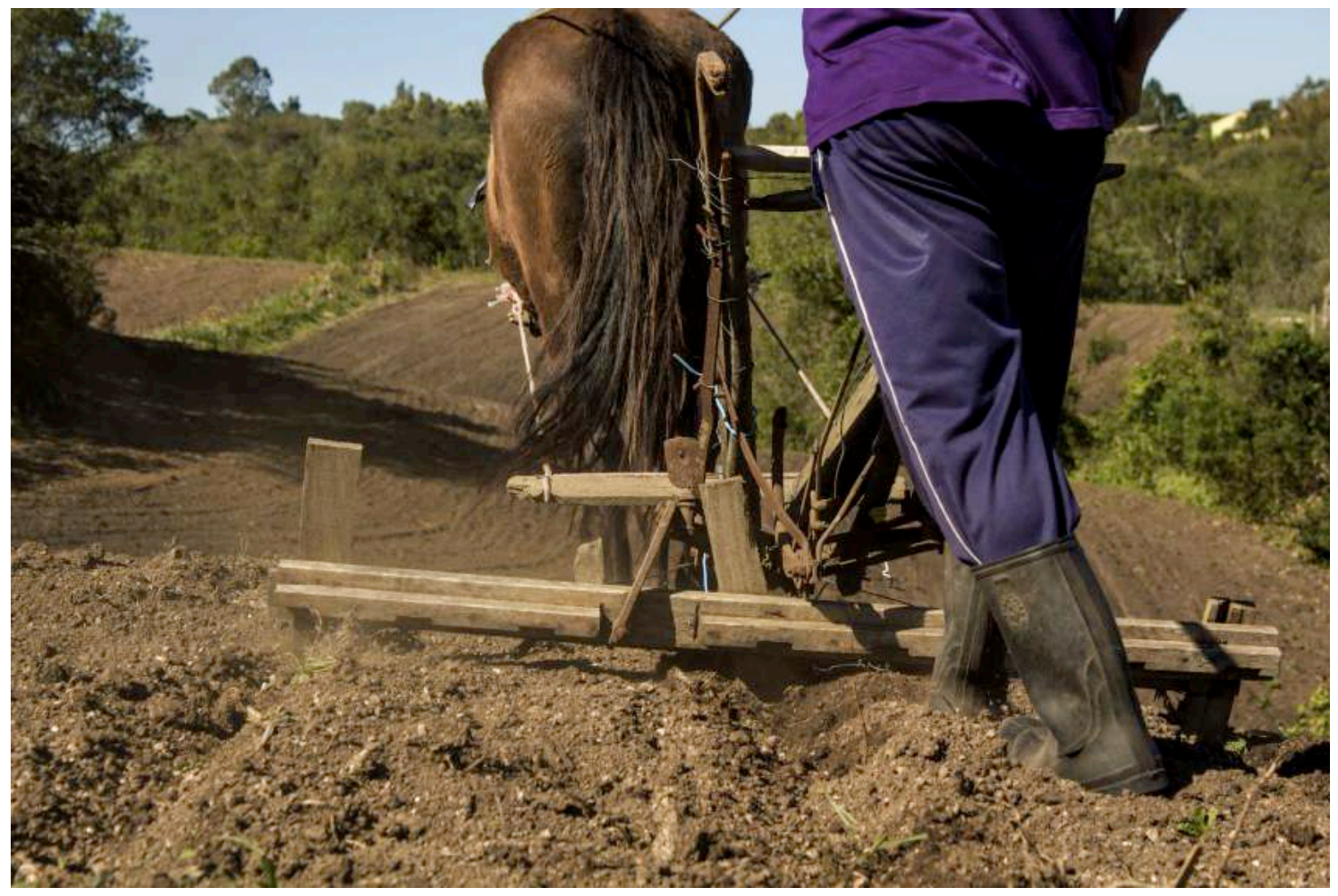

FOTO 1 - Seres (e) máquinas: Onécio, conjuntamente com o cavalo, utilizando a trilhadeira para fazer os canteiros onde serão plantados os feijões. (2016)

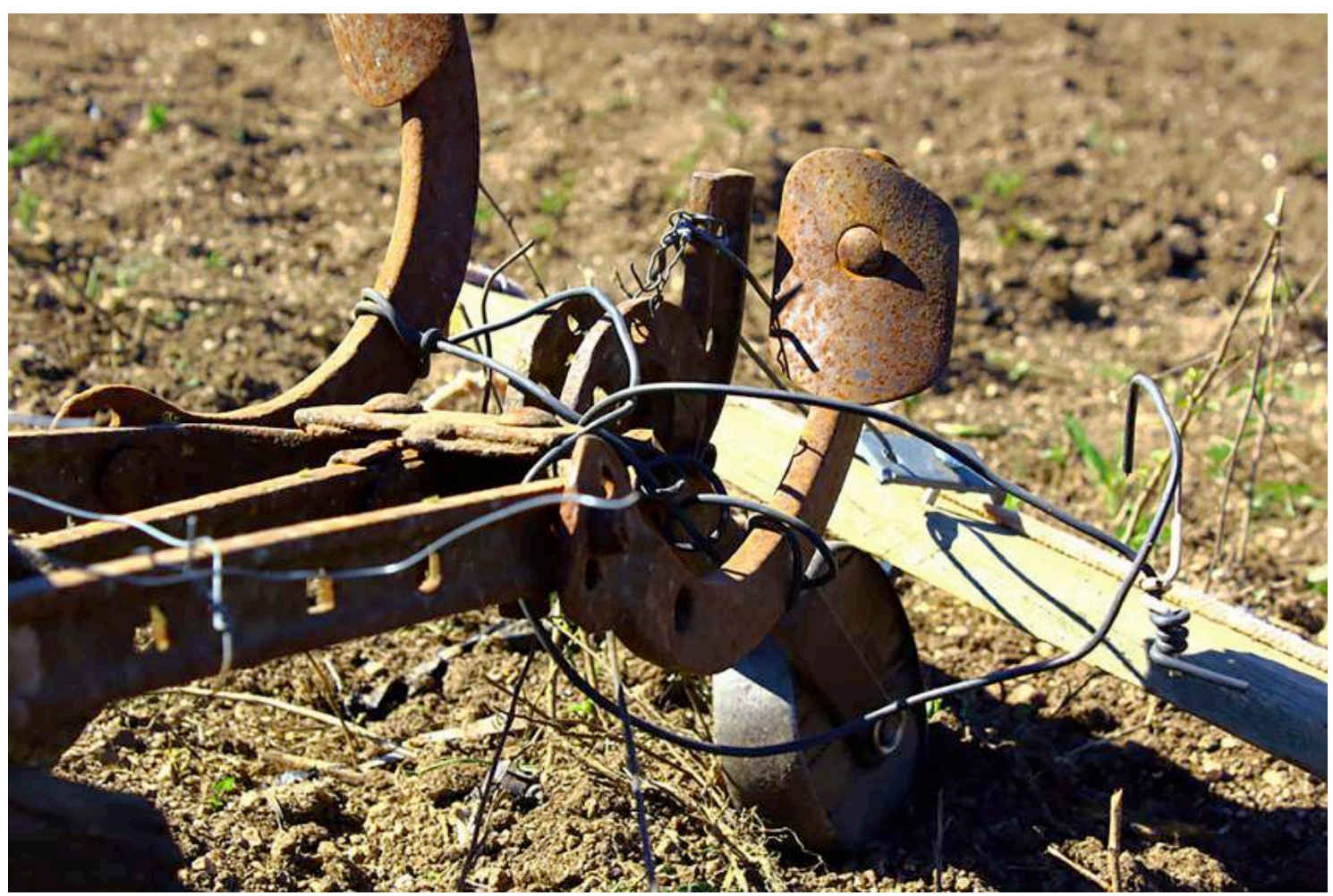

FOTO 2 - A invenção do cotidiano. Máquina adaptada pelo agricultor. (2016). 
ACENO, Vol. 4, N. 7, p. 333-339. Jan. a Jul. de 2017.

Ensaio fotográfico.

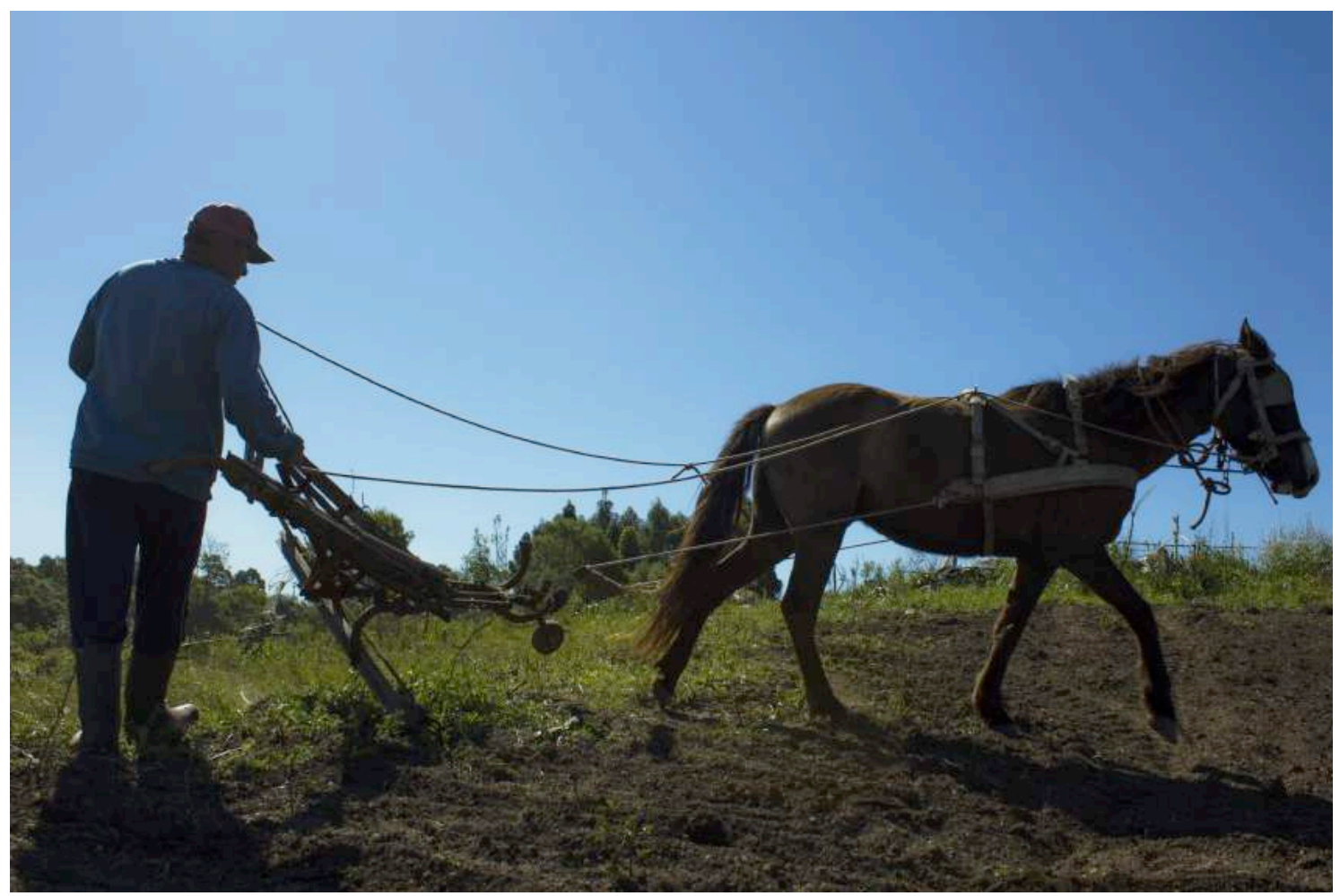

FOTO 3 - O viver "com”. (2016)

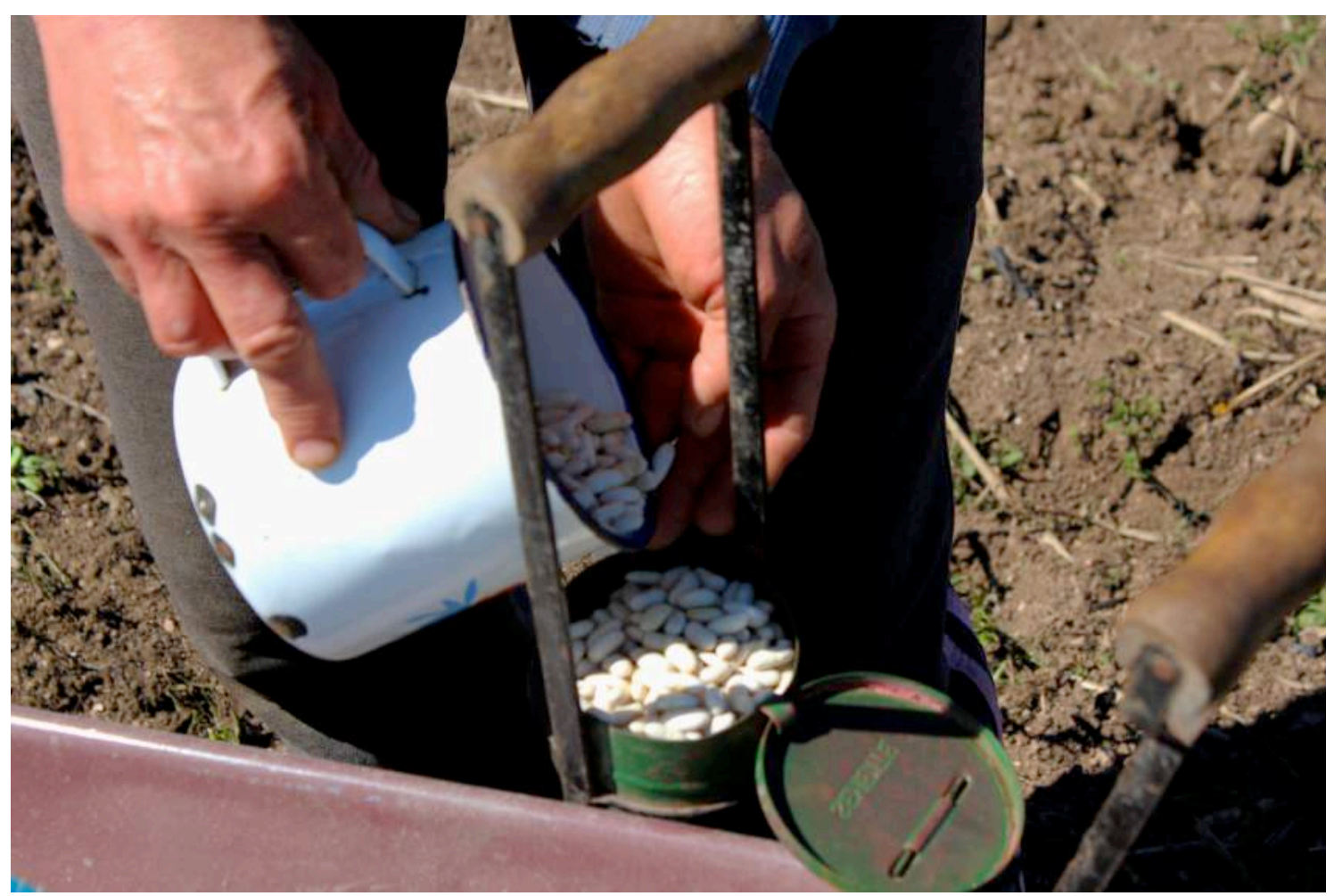

FOTO 4 - Plantar. (2016) 


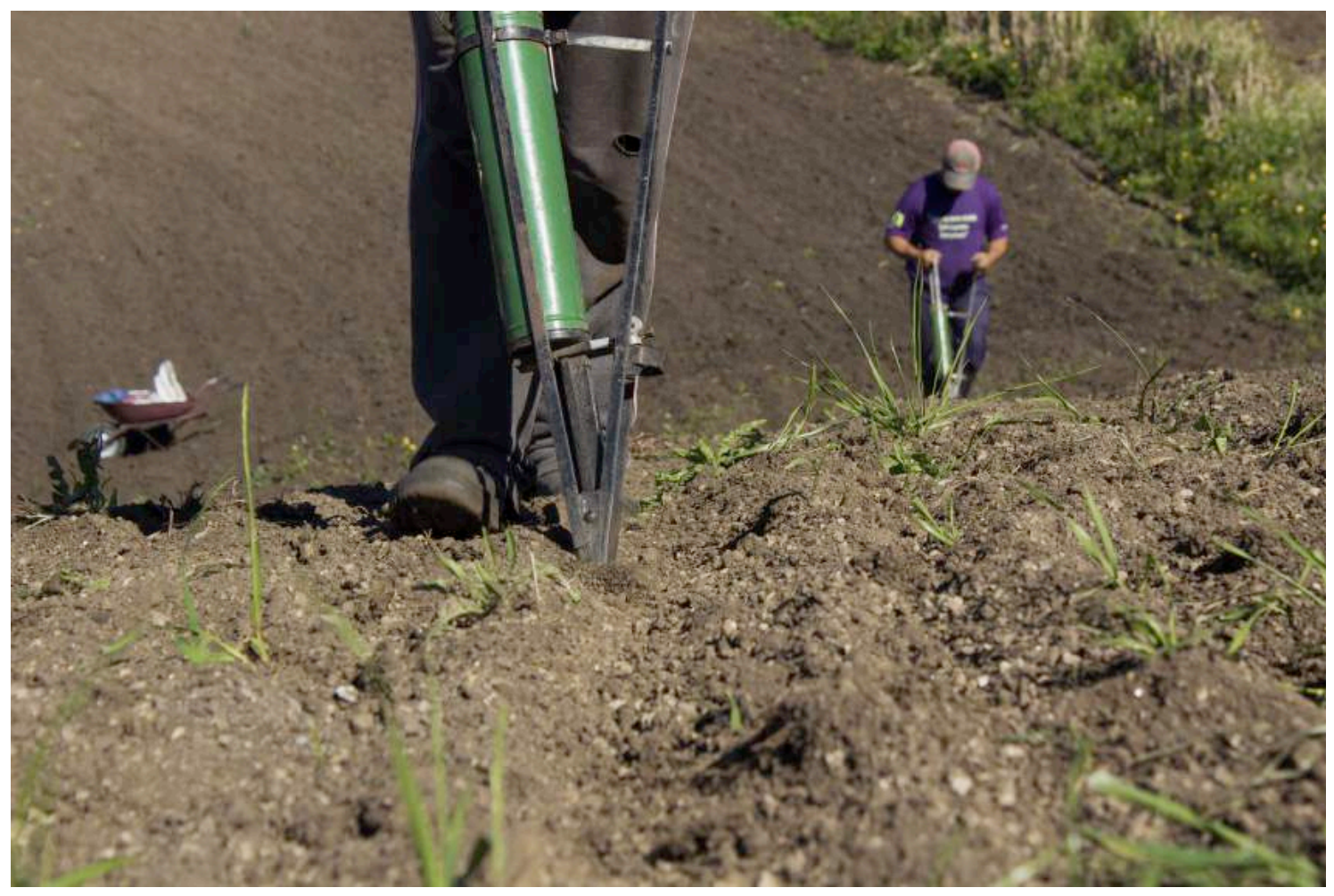

FOTO 5 - Sincronias nos espaços-tempos. (2016)

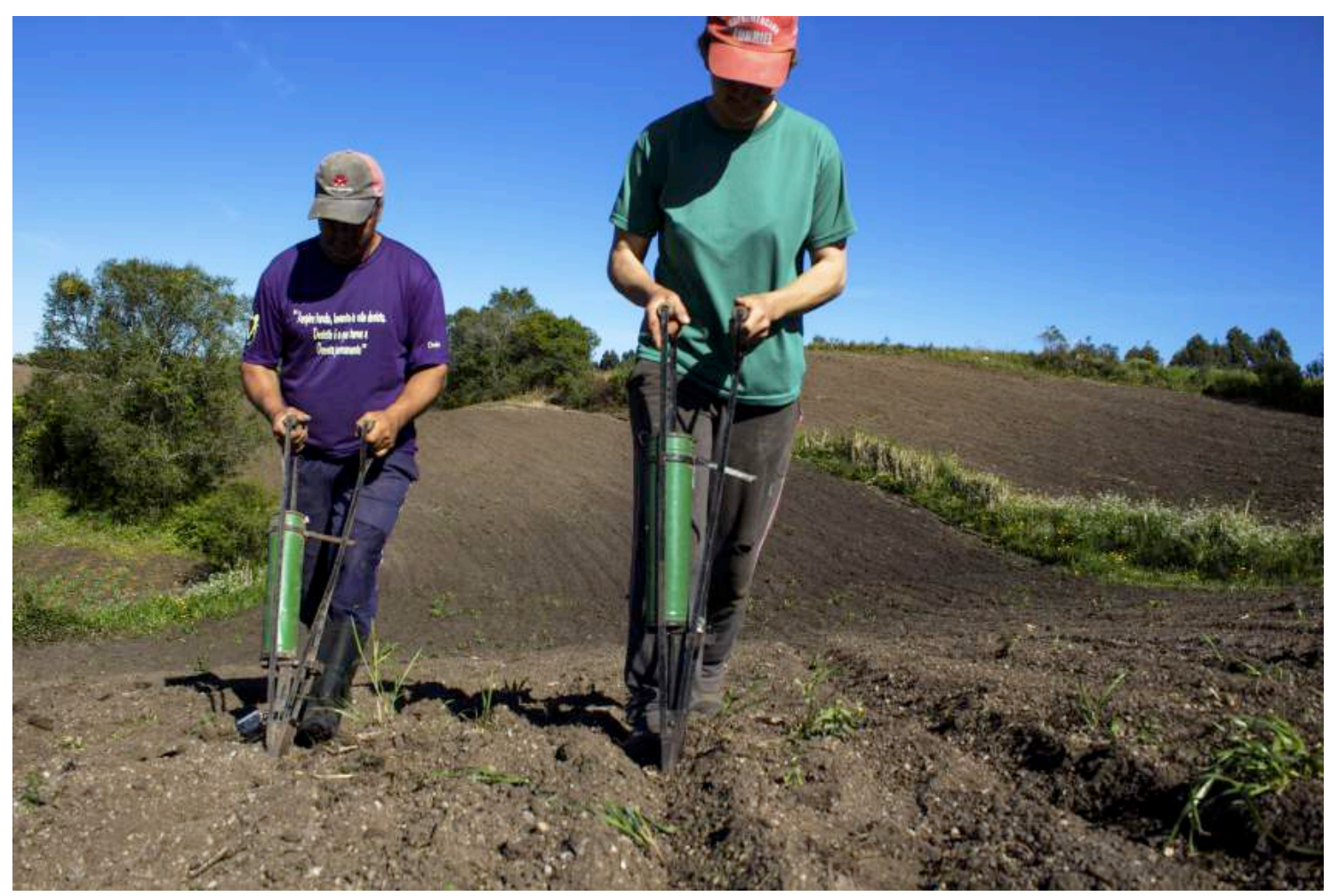

FOTO 6 - Habitar: um modo de vida conjunto. (2016) 




FOTO 7 - Cuidar. Onécio atento ao broto do feijão nascendo após dez dias do plantio. (2016)

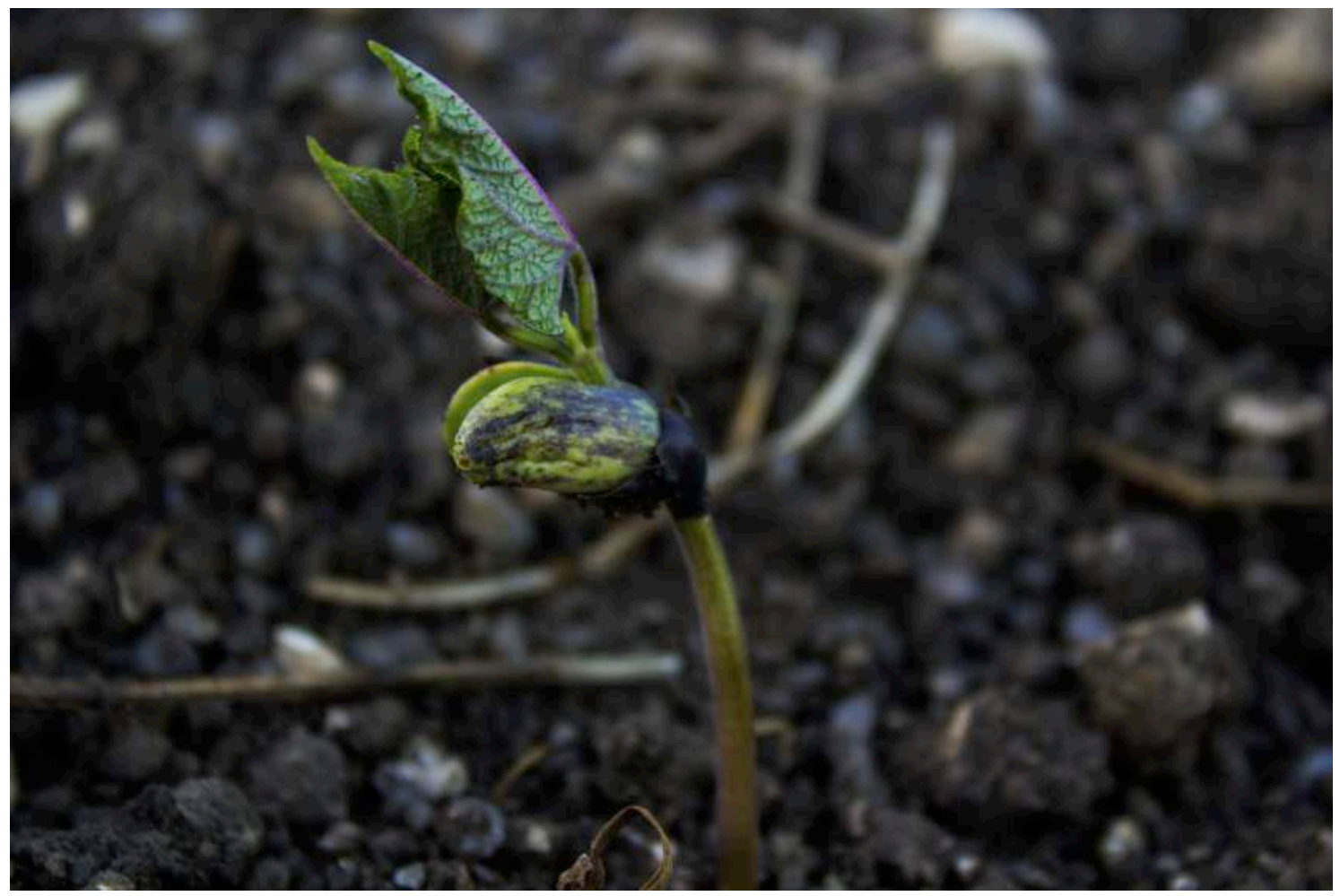

FOTO 8 - Brotar. Planta de feijão na lavoura com quinze dias após o plantio. (2016). 


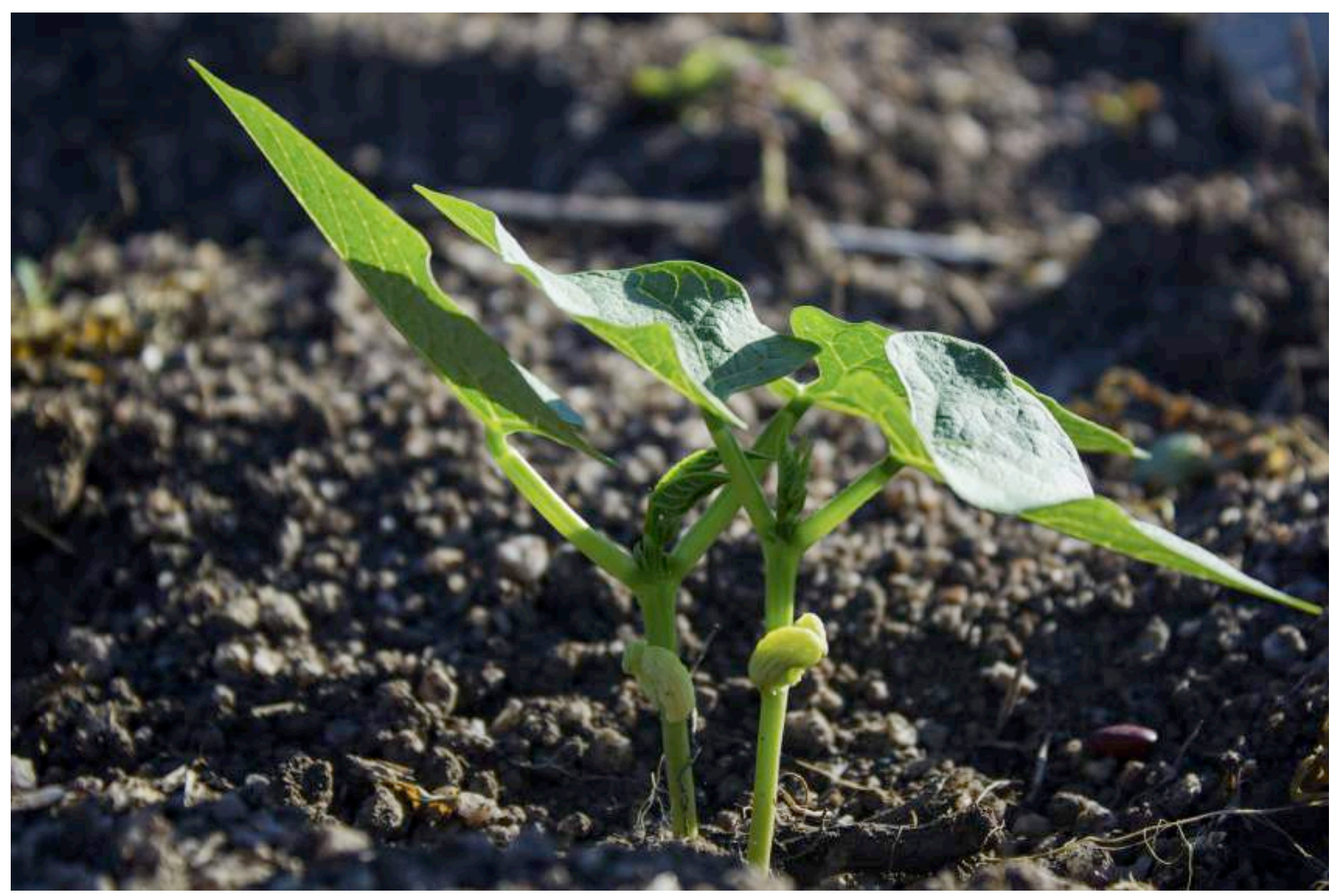

FOTO 9 - Crescer. Planta de feijão na lavoura com vinte e cinco dias após o plantio. (2016)

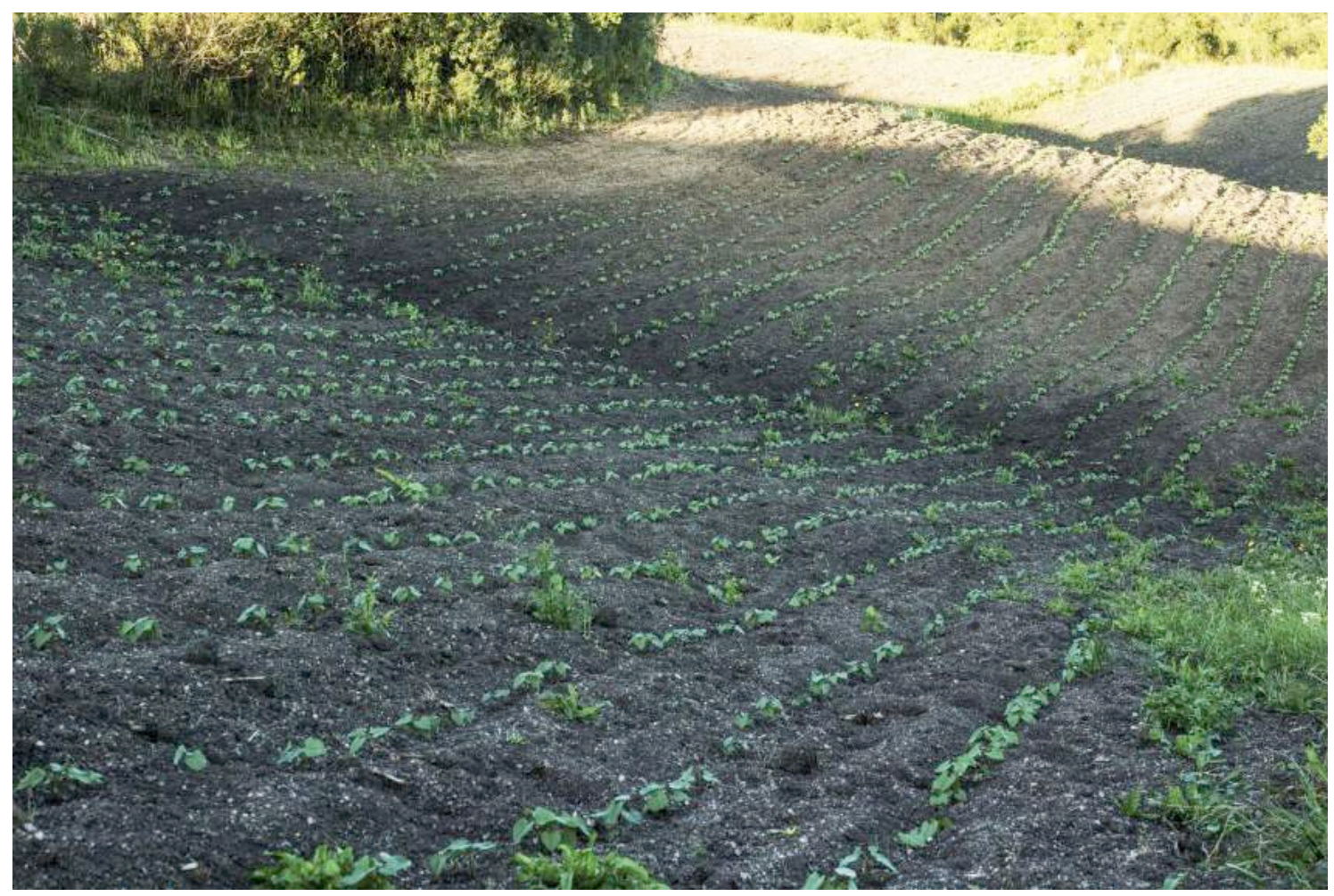

FOTO 10 - Coletivo de não-humanos. Lavoura de feijão com cerca de vinte dias após o plantio. (2016) 